\title{
O ESTUDO DA ETNOBOTÂNICA DAS PLANTAS MEDICINAIS NA ESCOLA
}

\section{The ethno-botanical study of medicinal plants at school}

\author{
Mara Luciane Kovalski ${ }^{1}$ • Ana Tiyomi Obara ${ }^{2}$
}

\begin{abstract}
Resumo: A valorização do conhecimento popular que os alunos trazem sobre as plantas medicinais potencializa o interesse destes sobre os conhecimentos científicos a serem trabalhados sobre o tema. Esta pesquisa teve como objetivo identificar: as concepções, conteúdos, estratégias didáticas e metodologias utilizadas pelas professoras do Ensino Fundamental, de uma escola rural de Maringá - PR, no desenvolvimento de um projeto voltado ao estudo das plantas medicinais. Na coleta dos dados, foram utilizadas as seguintes estratégias: observação participante, gravações orais e questionários. A análise dos dados foi feita mediante análise documental e análise de conteúdo. Os resultados evidenciam que a principal dificuldade observada no projeto foi a falta de domínio do conhecimento científico sobre o tema por parte das professoras. Em contrapartida, a pluralidade de metodologias e estratégias didáticas utilizadas pelas mesmas, organizadas na forma de projeto, indica que é possível romper com o ensino tradicional e viabilizar uma prática participativa e problematizadora.
\end{abstract}

Palavras-chave: Ensino de ciências. Estratégia didática. Etnoconhecimento. Pesquisa participante. Pluralismo metodológico.

\begin{abstract}
Valuing the folklore that students have on medicinal plants empowers their interest in scientific knowledge that can be worked into themes. Current research identifies the notions, contents, didactic strategies and methodologies used by primary schools teachers of a school in the rural area of Maringá PR Brazil in the development of a scientific project on the study of medicinal plants. The following strategies were employed for data collection: participant observations, speech recordings and questionnaires. Data analysis was performed by document and content analyses. Results show that the main problem was the fact that teachers lacked the scientific knowledge on the theme. On the other hand, several of the methodologies and didactic strategies used by the teachers show that it is possible to depart from traditional teaching and make possible participation and questioning.
\end{abstract}

Keywords: Science teaching. Pedagogic strategy. Ethno knowledge. Participant research. Methodological pluralism.

\footnotetext{
${ }^{1}$ Universidade Estadual de Maringá (UEM), Programa de Pós-graduação em Educação para a Ciência e a Matemática, Avenida Colombo, Jardim Universitário, CEP 87020-900, Maringá, PR, Brasil. E-mail: marinha.luciane@gmail.com

${ }^{2}$ Universidade Estadual de Maringá, Departamento de Biologia, Maringá, PR, Brasil.
} 
Kovalski, M. L.; Obara, A. T.

\section{Introdução}

Desde a Antiguidade, em diferentes épocas e culturas, o homem busca, no ambiente natural, os recursos para a sua sobrevivência e para a melhoria de sua qualidade de vida. Assim, toda a sociedade acumula um acervo de informações a respeito do ambiente em que está inserida, incluindo os conhecimentos relativos ao mundo vegetal com o qual está em contato (AMOROZO, 1996).

Peixoto Neto e Caetano (2005, p. 3) afirmam que "o ser humano tem empregado plantas como fonte de medicamentos para os males que o assolam, sendo bastante difícil ser encontrada uma civilização da antiguidade que não tenha se utilizado do grande poder de cura de diversas plantas". De acordo com os registros históricos da Antiguidade, o homem conhece as propriedades das plantas há vários milênios, pois sempre as utilizou de diversas maneiras: para a alimentação, aquecimento, construções e abrigo, vestuário e, em especial, com fins medicinais. Para alguns povos, a cura advinda das plantas tinha um caráter miraculoso e sobrenatural.

Embora a medicina tradicional, baseada no uso de ervas medicinais, esteja sustentada em uma história milenar, a partir do século XIX, com a obtenção de substâncias sintéticas com propriedades farmacológicas e com a síntese química de novos compostos, a utilização de derivados de plantas diminuiu consideravelmente. No entanto, a partir da década de 1960, o interesse e a procura por produtos fitoterápicos e as terapias naturais vêm aumentando gradativamente, inclusive em países desenvolvidos, sejam estes produtos in natura ou processados (CUNHA, 2003).

Com o aumento do consumo de fitoterápicos no Brasil, o Governo Federal criou, em 2006, a Política Nacional de Plantas Medicinais e Fitoterapia que tem como principal objetivo "garantir à população brasileira o acesso seguro e o uso racional de plantas medicinais e fitoterápicos, promovendo o uso sustentável da biodiversidade, o desenvolvimento da cadeia produtiva e da indústria nacional" (BRASIL, 2006, p. 20).

Em muitas comunidades, o uso das ervas é o principal recurso para o tratamento de diversas doenças, além de trazer uma grande economia para as famílias. Contudo, é preocupante o uso indiscriminado que muitas pessoas fazem das plantas medicinais, sem saber do risco, pois muitas destas plantas apresentam toxicidade elevada e precisam ser utilizadas de maneira correta, de preferência com acompanhamento médico.

Neste contexto, a escola é um dos principais, ou, talvez, o principal meio para que estas informações cheguem aos alunos de maneira clara e objetiva, pois "[...] o ensino e a aprendizagem que ocorrem nas salas de aula representam uma das maneiras de construir significados, reforçar e conformar interesses sociais, formas de poder, de experiência, que têm sempre um significado cultural e político" (SANTOMÉ, 1995, p. 166).

Além do conhecimento científico, é necessário destacar, também, a importância do conhecimento que os envolvidos ou a comunidade já detêm sobre as plantas medicinais, uma vez que seu uso faz parte do seu cotidiano, muitas vezes, há várias gerações.

Neste sentido, Silva (2006, p. 21) afirma que “[...] valorizar o conhecimento 'popular', o 'senso comum' das comunidades tradicionais ou dos grupos sociais minoritários é, também, contribuir para uma Educação Popular e favorecer a construção de um conhecimento socializado significativo". Lopes (1993, p. 16) ainda assegura que "rejeitar o senso comum ou criticá-lo passa a ser encarado como menosprezo ao saber popular e a qualquer forma de saber não científico". 
No ensino de Ciências, é consenso a importância de se valorizar e resgatar os saberes que os alunos trazem de suas vivências e experiências exteriores à escola. Além disto, sabe-se que a escola e o professorado não devem ignorar a diversidade de culturas existentes na sociedade, porém precisam encontrar estratégias e metodologias para incluir e dialogar com os diferentes conhecimentos pertencentes aos estudantes. Vivemos em um país que abriga ricas e diversas etnias e culturas, e negá-las ou rejeitá-las seria um descaso, tanto para com estas distintas formas de saberes quanto para com os próprios alunos.

Para Chassot (2006), a escola não pode ser vista apenas como repetidora ou reprodutora de conhecimentos, mas deve assumir uma postura mais crítica em relação à educação. $\mathrm{O}$ autor complementa: "[...] é preciso abandonar a assepsia. Há a necessidade de tornar o nosso ensino mais sujo, isto é, encharcá-lo na realidade" (CHASSOT, 2006, p. 98).

Santomé (1995, p. 165) enfatiza, ainda, que "[...] os currículos planejados e desenvolvidos nas salas de aula vêm pecando por uma grande parcialidade no momento de definir a cultura legítima, os conteúdos culturais que valem a pena."

Neste sentido, estudos e pesquisas que procuram investigar estratégias e metodologias de ensino que visam resgatar o conhecimento tradicional, num processo de diálogo com o saber científico, são fundamentais para a valorização da cultura popular e tradicional dos envolvidos.

Frente a estas constatações, a presente pesquisa partiu de dois problemas principais: será que os professores estão preparados para proporcionar o diálogo entre os diferentes saberes tradicionais/populares e científicos - valorizando, ao mesmo tempo, a cultura tradicional e a formação científica dos alunos? Quais os limites e avanços didáticos e pedagógicos necessários para viabilizar uma prática docente que articule o conhecimento tradicional/popular com o conhecimento científico?

Nesta perspectiva, a pesquisa teve como objetivo identificar: os conteúdos, as concepções, as estratégias didáticas e as metodologias utilizadas pelas professoras do primeiro ao quinto ano do Ensino Fundamental, de uma escola municipal localizada no município de Maringá, PR, durante o desenvolvimento de um projeto voltado ao estudo das plantas medicinais.

\section{A etnobotânica no currículo escolar}

Embora as plantas e sua história façam parte da evolução humana, pois o homem sempre fez uso das ervas em suas práticas médicas e religiosas, em seu folclore e na mitologia, de acordo com Albuquerque (2005), o termo etnobotânica só foi utilizado, pela primeira vez, em 1895, por J. W. Harshberger. O mesmo autor define a etnobotânica como "o estudo da interrelação direta entre pessoas de culturas viventes e as plantas do seu meio" (ALBUQUERQUE, 2005, p. 6, grifo do autor). Desta forma, estudar o relacionamento das sociedades tradicionais com o ambiente no qual estão inseridas é de fundamental importância, pois não há como dissociar esta interação.

Mas, foi somente a partir de meados do século XX que a etnobotânica passou a ser compreendida como "o estudo das inter-relações entre povos primitivos e plantas, acrescentandose uma componente cultural a sua interpretação pelo engajamento cada vez maior de antropólogos" (ALBUQUERQUE, 2005, p. 4).

$\mathrm{O}$ autor ainda afirma que a etnobotânica também tem como objetivos "investigar e estudar o uso de plantas com finalidades medicinais com o firme propósito de oferecer elementos 
Kovalski, M. L.; Obara, A. T.

práticos para outros investigadores nas áreas de fitoquímica e farmacologia, favorecendo a descoberta de novos medicamentos" (ALBUQUERQUE, 2005, p. 10).

Segundo Hamilton et al. (2003), a etnobotânica, como disciplina científica, é recente e ainda não foi sistematizada e formalizada como as demais ciências; no entanto, o autor a considera como uma disciplina-chave, na medida em que esta propõe uma ligação entre o conhecimento científico e o saber popular, e resgata e valoriza os conhecimentos tradicionais e a conservação dos recursos naturais. Desta forma, a etnobotânica vem ganhando reconhecimento e sendo devidamente valorizada por parte dos cientistas, na medida em que estes vêm percebendo sua função fundamental para o desenvolvimento dos povos.

Ao trabalhar com a temática plantas medicinais na escola, é importante estabelecer a associação entre os diferentes saberes que fazem parte deste conteúdo, pois acreditamos que é pelo diálogo entre as diferentes formas de conhecimento que se pode chegar a uma aprendizagem significativa sobre o tema. Por outro lado, com isto, não estamos dizendo "que o conhecimento científico deva ser substituído pelo conhecimento etnocientífico, mas utilizar desse conhecimento (popular) como uma ferramenta de mobilização cognitiva e afetiva do aluno para a percepção do novo conhecimento que se lhe apresenta: o científico" (COSTA, 2008, p. 165).

Autores como Brandão (2003), Chassot (2006), Lopes (1999), Mortimer (1998), Santomé (1995) e Perrelli (2008) defendem a ideia de que os saberes tradicionais/populares devem fazer parte do currículo escolar, uma vez que fazem parte da vida dos estudantes e precisam ser reconhecidos e explorados pela escola. Por sua vez, Lopes (1999, p. 137) afirma que "[...] o conhecimento cotidiano, como todos os demais saberes sociais, faz parte da cultura e é construído pelos homens das gerações adultas, que o transmitem às gerações sucessivas, sendo a escola um dos canais institucionais dessa transmissão."

Trabalhos como o de Perrelli (2008), realizados com grupos indígenas Kaiowá/Guarani, apontam para a elaboração de currículos pluriculturais, não só nas escolas indígenas, mas em todas as escolas brasileiras. A autora discute, também, a necessidade de

[...] se pensar, também, em práticas pedagógicas renovadas, culturalmente orientadas, que respeitem as diferenças, as lógicas e os estilos de aprendizagem de cada cultura, e que estejam comprometidas com a elaboração de projetos coletivos de empoderamento dos povos culturalmente subordinados. (PERRELLI, 2008, p. 394)

Nesta mesma perspectiva, Arenas e Cairo (2009) afirmam, ainda, que o grande desafio da escola moderna está em articular os conhecimentos tradicionais dentro dos currículos escolares convencionais, uma vez que a ciência exerce uma hegemonia epistemológica por meio da escola moderna, condenando e marginalizando qualquer conhecimento alternativo ou cultura local. Para os autores, currículos plurais, que possibilitem o diálogo dos saberes, podem, efetivamente, despertar, nos alunos, valores éticos para que estes possam lidar com os dilemas culturais e problemas socioambientais de sua realidade imediata. 
O estudo da etnobotânico das plantas medicinais ...

\section{Metodologias e estratégias didáticas no ensino de ciências}

No ensino de ciências, as metodologias e estratégias didáticas são variadas, e possibilitam, aos professores, planejarem inúmeras atividades que permitam a compreensão dos alunos acerca dos conteúdos curriculares, de maneira a instigá-los a participarem das aulas.

Para Krasilchik (2004, p. 77), "qualquer curso deve incluir uma diversidade de modalidades didáticas, pois cada situação exige uma solução própria; além do que, a variação das atividades pode atrair e interessar os alunos, atendendo às diferenças individuais". A autora enfatiza que diferentes modalidades didáticas podem ser utilizadas pelos professores durante as aulas, dentre elas: aulas expositivas, discussões, demonstrações, aulas práticas, excursões, simulações, instrução individualizada e projetos.

Cachapuz, Praia e Jorge (2002) discutem sobre as perspectivas para o ensino das ciências: Ensino por Transmissão (EPT), Ensino por Descoberta (EPD), Ensino para a Mudança Conceptual (EMC) e Ensino por Pesquisa (EPP). Esta última, segundo muitos autores, vem ao encontro das expectativas de grande parte dos pesquisadores da didática das Ciências, pois "reúne consenso alargado em relação às suas potencialidades na construção de conhecimentos, contribuindo positivamente para a formação pessoal e social dos alunos" (LOPES; BETTENCOURT, 2009, p. 508).

Os professores precisam aprender a ensinar ciências utilizando-se de metodologias e estratégias de ensino inovadoras, para, assim, despertarem, nos alunos, o interesse pelas ciências (CACHAPUZ; PRAIA; JORGE; 2002). Neste contexto, o Ensino por Pesquisa "fundamentase na epistemologia racionalista contemporânea, segundo a qual a Ciência desenvolve teorias para um melhor entendimento do Mundo Natural" (LUCAS; VASCONCELOS, 2005, p. 3). Ainda, segundo as autoras, as diferentes metodologias e estratégias didáticas "devem proporcionar aos alunos a integração de conceitos e devem fomentar neles a análise dos seus próprios métodos de trabalho (metacognição), porém estando sempre presente o pluralismo metodológico" (LUCAS; VASCONCELOS, 2005, p. 5).

Já a metodologia de projetos adotada neste estudo, pode despertar o interesse dos alunos e os motivar a participarem das aulas, desde que a proposta seja bem elaborada pelos professores, numa perspectiva de investigação.

\section{Metodologia da pesquisa}

Dentre as diversas vertentes da pesquisa qualitativa, a pesquisadora optou pela metodologia da Pesquisa Participante (BRANDÃO, 1984), considerando os objetivos do trabalho, além da possibilidade de voltar os olhares ao ensino contextualizado do conhecimento científico e do saber popular.

A característica principal da Pesquisa Participante é, justamente, a participação e a inserção, tanto do pesquisador como dos sujeitos pesquisados, no estudo. Brandão $(1984$, p. 10) afirma que os "pesquisadores e pesquisados são sujeitos de um mesmo trabalho comum, ainda que com situações e tarefas diferentes". Nesta pesquisa, realizada nos meses de abril a dezembro de 2010, a comunidade escolar teve uma participação ativa no planejamento e no desenvolvimento das atividades do projeto desde o início do trabalho. A pesquisadora da universidade 
Kovalski, M. L.; Obara, A. T.

(pós-graduanda) acompanhou, participou e observou todos os momentos envolvidos neste estudo.

A comunidade envolvida em uma Pesquisa Participante é beneficiada com os resultados obtidos a partir da participação e da cooperação estabelecida entre seus membros, durante o planejamento e o desenvolvimento das atividades, na busca de resolverem problemas reais (GIANOTTEN; WIT, 1984; THIOLLENT, 1986).

A seleção da escola onde a pesquisa foi realizada não foi aleatória. Trata-se de uma escola rural localizada no município de Maringá, cujo grupo de professores e profissionais apresenta um diferencial: são bastante preocupados e dedicados à formação cidadã dos alunos. As questões sociais e ambientais já eram contempladas em várias pesquisas e projetos desenvolvidos na escola, sendo a instituição premiada em vários concursos e eventos.

A instituição de ensino atendia em 2010, ano em que foi realizada a pesquisa, um total de 222 alunos do $1^{\circ}$ ao $9^{\circ}$ ano. Destes, cem são alunos do $1^{\circ}$ ao $5^{\circ}$ ano, e 122 , do $5^{\circ}$ ao $9^{\circ}$ ano, sendo que $40 \%$ dos alunos matriculados são moradores da zona rural, enquanto os demais moram na cidade de Maringá ou na periferia da zona urbana. A escola conta, ainda, com cinco funcionários e vinte docentes.

Participaram do projeto "O Estudo das Plantas Medicinais": nove professoras do $1^{\circ}$ ao $5^{\circ}$ ano do Ensino Fundamental, além da diretora e da supervisora escolar, alunos, pais e funcionários da escola, totalizando cento e cinquenta participantes. As atividades foram desenvolvidas por todas as professoras em todas as turmas do $1^{\circ}$ ao $5^{\circ}$ ano simultaneamente. No entanto, neste estudo, observou-se, de forma sistemática, apenas uma turma. Assim, foram observadas e gravadas, em áudio, um total de 24 aulas em uma turma do $3^{\circ}$ ano. O perfil das professoras participantes é apresentado no Quadro 1.

Seis daquelas professoras têm formação em Pedagogia, duas em Letras e uma em Educação Física. Uma delas tem mestrado e sete são especialistas. À época da pesquisa, duas professoras possuíam menos de cinco anos de experiência e cinco tinham mais de 18 anos de experiência.

Quadro 1. Perfil das professoras participantes.

\begin{tabular}{|l|c|l|c|l|}
\hline Participante & Sexo & \multicolumn{1}{|c|}{ Formação } & $\begin{array}{c}\text { Experiência profissional no Ensino } \\
\left.\text { Fundamental } \mathbf{( 1}^{\circ} \text { ao } \mathbf{5}^{\circ} \text { ano }\right)\end{array}$ & Pós-graduação \\
\hline P-1 & F & Pedagogia & 19 anos & Pedagogia Escolar \\
\hline P-2 & F & Letras & 19 anos & Educação Especial \\
\hline P-3 & F & Pedagogia & 25 anos & Educação Especial \\
\hline P-4 & F & Educação Física & 16 anos & Gestão Pública e Educacional \\
\hline P-5 & F & Pedagogia & 30 anos & Direção, orientação e supervisão \\
\hline P-6 & F & Pedagogia & 1 ano & Educação especial \\
\hline P-7 & F & Letras & 4 anos & Mestrado \\
\hline P-8 & F & Pedagogia & 29 anos & ----- \\
\hline P-9 & F & Pedagogia & 12 anos & Gestão e metodologia didática \\
\hline
\end{tabular}

Fonte: elaborado pelas autoras. 
Como instrumentos de coleta de dados, foram utilizados: a observação participante, gravações orais ${ }^{3}$, arquivo de fotos, diário de campo e aplicação de questionário.

$\mathrm{O}$ início das atividades desta pesquisa foi precedido pela aplicação de um questionário às professoras, no intuito de verificar os conhecimentos que estas possuíam com relação às plantas medicinais; se faziam uso das mesmas, como o faziam, quais plantas eram utilizadas e com qual finalidade; com quem aprenderam a utilizar as plantas medicinais; se costumavam falar sobre estas plantas com seus alunos, em qual ano, e dentro de qual conteúdo o faziam; se trabalhavam com o conhecimento científico referente às plantas medicinais ou se citavam apenas o conhecimento popular, bem como de que forma trabalhavam estes conhecimentos.

A partir das falas e dos depoimentos obtidos por meio do questionário e das gravações orais, optou-se pela análise das falas significativas, de acordo com Brandão (2003). Neste método de análise, as falas significativas "representam uma expressão de um pensamento, de um saber, quando se parte do princípio de que em qualquer pessoa humana há um crescendo de conhecimento vivenciado e acumulado sob a forma de uma integração cultural de saberes" (BRANDÃO, 2003, p. 142, grifo do autor).

Cabe lembrar que o projeto de pesquisa foi submetido ao Comitê de Ética em Pesquisa da Universidade Estadual de Maringá, PR, o qual aprovou a pesquisa, seus fundamentos e metodologia.

\section{Resultados e discussão}

\section{Os primeiros passos da pesquisa}

Esta pesquisa se concretizou após alguns encontros da pesquisadora (pós-graduanda) e sua orientadora com as professoras envolvidas, supervisora e direção escolar.

No primeiro encontro, foi discutida a proposta de se desenvolver um trabalho voltado ao estudo das plantas medicinais à direção e supervisão escolar. Neste momento, foram esclarecidos os objetivos e as condições para a realização da pesquisa. A direção escolar - conhecedora dos possíveis benefícios oriundos desse projeto - solicitou-nos o encaminhamento do mesmo à Secretaria Municipal de Educação de Maringá para a aprovação.

Com o consentimento da Secretaria de Educação, deu-se início à pesquisa; assim, marcamos um segundo encontro com as professoras do $1^{\circ}$ ao $5^{\circ}$ ano do Ensino Fundamental, e as convidamos para participarem da pesquisa. De imediato, percebemos o interesse das educadoras pelo trabalho e a vontade de envolverem seus alunos no mesmo. Prontamente, marcaram um encontro para discutir e planejar as atividades, metodologias e estratégias a serem utilizadas no desenvolvimento do projeto "O Estudo das Plantas Medicinais".

${ }^{3}$ Gravador MP3. 
Kovalski, M. L.; Obara, A. T.

O trabalho com projetos já faz parte da realidade desta escola; neste sentido, a instituição adotou a proposta como um projeto a ser realizado durante o ano letivo de 2010, incluindo-o no Plano de Ação da escola. Barbosa (2000, p. 73) descreve que a pedagogia de projetos é constituída de "uma ação concreta e voluntária que é decidida tendo em vista a obtenção de um alvo informativo. É saber partir, na prática escolar, de uma situação-problema e global dos fenômenos, da realidade fatual e não da interpretação teórica já sistematizada nas disciplinas".

No terceiro encontro, um questionário inicial sobre plantas medicinais foi respondido pelas professoras, visando identificar suas concepções e práticas a respeito do tema.

Das nove professoras envolvidas neste estudo, seis responderam ao questionário. As professoras disseram conhecer e fazer uso de 18 plantas medicinais diferentes, sendo que as mais citadas e utilizadas por elas foram: boldo, hortelã, guaco, babosa, arnica e camomila.

Quando questionadas "Com quem você aprendeu a utilizar as plantas medicinais?", as professoras responderam: familiares, literaturas especializadas, cursos, e com pessoas mais velhas (mães, tios, avós).

A respeito da questão "Em suas aulas você costuma falar sobre as plantas medicinais? Em qual ano e dentro de qual conteúdo?”, apenas duas professoras disseram abordar este conteúdo em sala de aula, e as demais alegaram que este conteúdo não faz parte do currículo dos anos em que ministram aulas. Seguem as justificativas das professoras que não trabalham este conteúdo com seus alunos:

- "Não, por não ser conteúdo de minha área, mas poderia desenvolver diferentes atividades, visando a qualidade de vida". (P-4)

- "A série que trabalho não aborda este conteúdo". (P-3)

Diante destes registros, percebe-se que a escola não tem inserido as questões que envolvem as etnociências, pois, de acordo com as respostas obtidas, a maioria das professoras não discute e nem trabalha os saberes que envolvem as plantas medicinais com os alunos.

Este fato pode estar relacionado à falta de iniciativa, ou mesmo, à falta de tempo, por parte das professoras, em trabalhar com a questão da pluralidade cultural que envolve as plantas medicinais, em sala de aula; ou, ainda, durante a sua formação, estas professoras não tiveram acesso à necessidade de se abordarem outras formas de saber: popular, tradicional e saberes do cotidiano.

Cobern e Loving (2001) consideram necessária a inserção dos conhecimentos tradicionais no ensino de ciências, desde que as diferenças entre estes e o conhecimento científico sejam problematizadas. Os autores acreditam que esta é uma possibilidade de informar, aos alunos, as diferentes maneiras pelas quais a humanidade constrói seus conhecimentos, ampliando a visão dos mesmos sobre o mundo.

Brasil (2007, p. 13) enfatiza que o papel da escola é, também, proporcionar, aos educandos, “o direito à cultura, às artes, à diversidade de linguagens e formas de comunicação, aos sistemas simbólicos e ao sistema de valores que regem o convívio social, à formação como sujeitos éticos". Neste contexto, Moreira e Candau (2003) enfatizam que é por meio do currículo que iremos abrir espaço para a diversidade. 
Duas professoras disseram trabalhar com a temática em sala de aula e, quando questionadas sobre "Você trabalha com o conhecimento científico das plantas medicinais ou cita o conhecimento popular? Justifique", elas responderam:

- "Como não é especificamente conteúdo da série que estou atuando dificilmente trabalho com o conhecimento científico". (P-1)

- "Trabalho o conhecimento científico e popular, através de coleta de impressões com os alunos, pesquisa com os familiares, livros e internet". (P-2)

A professora 1 deixou claro que, praticamente, não aborda o conhecimento científico; e, na resposta da professora 2, é perceptível sua preocupação em valorizar os conhecimentos prévios dos alunos, estratégia que ela denomina coleta de impressões.

Em relação à última questão: "De que forma você trabalha estes conhecimentos?", obtivemos apenas uma resposta, na qual, verificou-se que a professora utiliza diferentes metodologias e estratégias para trabalhar tanto o conhecimento científico quanto o popular.

- "Através de conversas, pesquisa, leitura de textos informativos. Coleta de mudas entre os alunos, pesquisa de receita e valor medicinal". (P-2)

Com a aplicação do questionário, percebeu-se que a maioria das professoras nunca havia trabalhado com a temática plantas medicinais, no entanto, elas concordaram em participar de uma pesquisa voltada ao estudo destes vegetais.

\section{O planejamento do projeto}

O quarto encontro foi realizado para a elaboração do planejamento, ocasião em que foram traçadas algumas estratégias e metodologias a serem desenvolvidas no projeto "O Estudo das Plantas Medicinais". Participaram do processo: as professoras, a diretora, a supervisora escolar e a pesquisadora.

A temática em questão - Plantas Medicinais - foi considerada como "tema gerador", no qual os conteúdos a serem ensinados resultam de uma metodologia dialógica voltada para aprendizagem global, interdisciplinar e não fragmentada (FREIRE, 1987).

Para dar início ao projeto, as professoras pensaram em problematizar com algumas questões sobre a temática em estudo. As professoras também decidiram pelo envolvimento das famílias dos alunos neste estudo e enviaram um questionário, a ser respondido pelos familiares de cada aluno, no intuito de verificar quais plantas medicinais eram conhecidas pelos mesmos, como e com qual finalidade eram utilizadas.

Em seguida, discutiu-se como trabalhar o conhecimento científico em relação às plantas medicinais em sala de aula. Assim, algumas professoras sugeriram que isto poderia ser feito por meio de textos informativos, de visitas ao horto medicinal da universidade e da exibição de vídeos sobre o assunto. A respeito deste tópico a supervisora argumentou: 
Kovalski, M. L.; Obara, A. T.

\begin{abstract}
"Aí, por turma, a gente poderia então, aprofundar o conhecimento científico [...]. E aí eu acho assim. Nós deveríamos estar pensando em alguma coisa que pudesse... que fizesse os alunos pensar mais. Por exemplo, uma visita... de repente na Universidade Estadual de Maringá, ver se lá tem alguma coisa que a gente pode... sair ver estas plantas, se tem algum filme... que seria instrumento, aí eu to pensando assim, trazer instrumentos que possam estar dando pra eles mais suporte sobre o conhecimento científico". (Supervisora escolar)
\end{abstract}

Naquele momento, as professoras foram informadas de que um material de apoio seria elaborado, pela pesquisadora da Universidade Estadual de Maringá (UEM) participante do projeto, com informações científicas sobre as plantas medicinais que seriam cultivadas no horto medicinal a ser construído na escola, para subsidiar as professoras em sua prática.

Foi estabelecida, ainda, a realização de uma assembleia no salão nobre da escola, ao final do projeto, com todos os alunos, durante a qual cada turma responsável por uma meta apresentaria a pesquisa realizada sobre determinada planta medicinal, com o intuito de disseminar as atividades e socializar os saberes levantados.

Destaca-se que o envolvimento e a participação da direção e da equipe pedagógica no planejamento e desenvolvimento do projeto, sempre incentivando e orientando as professoras para a importância e o cumprimento de todas as etapas preestabelecidas, foram essenciais. Desta forma, foi possível visualizar um trabalho colaborativo e harmonioso entre os envolvidos, aspectos fundamentais para o planejamento e a concretização do projeto. Segundo os PCN, "o desenvolvimento do projeto requer tempo para análise, discussão e reelaboração contínua, o que só é possível em um clima institucional favorável e com condições objetivas de realização" (BRASIL, 1997, p. 36).

É notória a possibilidade que a Pesquisa Participante oferece no sentido de dar voz ativa aos sujeitos envolvidos no processo, na medida em que estes se organizam, planejam e desenvolvem coletivamente as atividades propostas. Assim, os participantes são estimulados a se comprometerem, pois são eles os autores e atores da pesquisa (BRANDÃO, 2003).

No quinto encontro, as professoras definiram o início das atividades do planejamento, e elaboraram um questionário a ser entregue aos alunos - para responderem em casa, com seus familiares - a respeito do uso e do conhecimento das plantas medicinais. Este questionário teve como objetivo investigar se os familiares dos alunos utilizavam plantas medicinais, quais eram estas, e com qual finalidade as utilizavam. Após estes encontros, em sala de aula, as professoras deram início às atividades planejadas.

\title{
O horto medicinal
}

A construção do horto medicinal teve como finalidade proporcionar, aos alunos e professores, um contato direto e prático com estes vegetais, tão importantes e benéficos a nossa saúde, se utilizados de maneira correta; além de criar um ambiente o qual os professores pudessem utilizar com seus alunos, pedagógica e didaticamente; o local também serviu de fonte de discussões, diálogos, resgate e valorização do conhecimento popular e tradicional sobre as plantas que lá se encontram. Desta forma, acreditamos que este espaço pode proporcionar: 
[...] a integração do saber popular e científico, sendo local destinado à pesquisa e estudo, é um espaço educativo e didático, para conhecimento da natureza e das plantas medicinais, aromáticas e condimentares, promotor do contato com a vida estimulando ações de preservação da natureza, evitando o extrativismo e possibilitando trocas de conhecimentos entre as pessoas. Portanto, o horto produz plantas com qualidade, preserva a natureza e valoriza a biodiversidade, reconhece corretamente as plantas medicinais evitando trocas e equívocos. (WERMANN; VELLOSO; FUSIGER, 2007, p. 673)

Sendo assim, toda a comunidade escolar poderá se beneficiar deste espaço, criado coletivamente, para fins de trocas de experiências e saberes. Dias e Janeira (2005, p. 116) destacam que tal ambiente constitui-se "[...] um local aprazível para o descanso do espírito, onde confluem as utilidades múltiplas das plantas que frequentemente podem ser usadas como alimento condimento e medicina, sendo simultaneamente belas".

Para a implantação do horto medicinal, a escola recebeu, por meio do projeto "Plantas Medicinais", desenvolvido desde 2003 pela Itaipu Binacional, cinquenta e sete (57) espécies de plantas medicinais. A construção do horto foi um trabalho coletivo, com a participação de toda a comunidade escolar durante o período letivo e, também, nos finais de semana. Como a escola já trabalhava com a reciclagem de materiais, os canteiros foram construídos com garrafas pet.

\title{
Desenvolvimento e aplicação do planejamento com os alunos
}

Seguindo o planejamento, as professoras iniciaram as atividades com três questões, como forma de problematizar a temática em estudo: $\mathrm{O}$ que são plantas medicinais? Para que elas servem? Como são usadas? Neste momento, estabeleceu-se um diálogo entre a professora e os alunos, e as questões foram respondidas coletivamente.

De acordo com Delizoicov e Angotti (2000), problematizar consiste em apresentar questões e situações a serem discutidas com os alunos, objetivando motivá-los à introdução de um conteúdo específico, procurando associá-lo à realidade, conhecida, presenciada e vivenciada por eles e para a qual não dispõem de conhecimentos científicos suficientes para interpretá-la total ou corretamente. Este primeiro momento poderá ocorrer, pelo menos, em dois sentidos. De um lado, pode ser que os alunos já tenham certo conhecimento em relação às questões expostas, adquirido de uma aprendizagem anterior, na escola ou fora dela. De outro lado, a problematização poderá permitir, ao aluno, sentir a necessidade de adquirir outros conhecimentos por ele ainda não detidos; ou seja, se vê colocado diante de um problema a ser resolvido.

\author{
[...] Professora: As plantas medicinais elas? \\ Alunos: Curam. \\ Professora: Elas curam. Mas o que é curar? \\ Aluno: Sarar... \\ $[\ldots]$ \\ Professora: Tá, mas como? Como que a gente pode usar?
}


Kovalski, M. L.; Obara, A. T.

Aluno: Pra curar machucado.

Aluno: Pra remédio, é... xarope.

Professora: Tá, então as plantas medicinais podem ser usadas na forma de

xarope.

Aluno: Cbá.

Aluno: Suco.

Aluno: Remédio.

Professora: O que mais?

Aluno: Compressa.

Ao término desta aula, a professora entregou, aos alunos, um questionário, que deveria ser respondido em casa com os familiares, sobre o conhecimento e uso das plantas medicinais.

$\mathrm{Na}$ aula seguinte, a professora e os alunos elaboraram um cartaz, com os resultados dos questionários previamente respondidos em casa, com suas famílias. Esta atividade exigiu uma sistematização e organização das principais ideias contidas no questionário. Tais ideias foram transcritas numa cartolina, pois seriam apresentadas aos demais colegas da escola, durante a assembleia, com o intuito de socializar os conhecimentos.

Nas aulas posteriores, a professora em observação, elaborou alguns textos informativos a respeito das plantas medicinais - "A importância das plantas medicinais", "Como coletar, armazenar e conservar as plantas medicinais", "Cuidados e orientações que devemos ter com os remédios vegetais" - para isto, ela se utilizou do material de apoio oferecido pela pesquisadora. Os textos proporcionaram, tanto aos alunos quanto à professora, maiores esclarecimentos sobre a temática em estudo.

De acordo com o planejado, as professoras levaram os alunos para visitar o Horto Didático Medicinal Professora Irenice Silva, localizado na Universidade Estadual de Maringá. Todos os alunos do $1^{\circ}$ ao $5^{\circ}$ ano puderam conhecer o referido local, cuja visita objetivou aprofundar os conhecimentos científicos dos alunos em relação às plantas medicinais, bem como mostrar o que é um horto medicinal e como este é estruturado, para possível implantação de um horto na escola.

Os alunos puderam conhecer várias espécies de plantas medicinais, cultivadas naquele local, bem como para que e de que forma são utilizadas. Ao retornarem para a escola, sob orientação da professora, os alunos fizeram, coletivamente, um relatório da visita, enumerando todas as plantas observadas e quais foram as explicações dadas pelos monitores sobre o emprego de cada uma delas.

Cada turma havia ficado responsável por estudar duas plantas medicinais, para isto, com a mediação da professora responsável, fizeram pesquisa em livros e textos informativos, realizaram o plantio das mudas em estudo, e observaram o desenvolvimento das mesmas no horto medicinal da escola. Com estas atividades, os alunos puderam aprender um pouco sobre cada planta medicinal em estudo - suas propriedades medicinais, seus nomes populares e científicos, local de origem, descrição botânica, morfologia e fisiologia, entre outros.

A professora do $5^{\circ}$ ano promoveu, ainda, uma oficina para a produção de velas e sabonetes, utilizando a tintura da citronela, com os alunos do $5^{\circ}$ ano, algumas mães e os representantes das demais turmas. Para a realização desta oficina, houve a colaboração de uma profissio- 
nal da Secretaria de Educação do município, que foi até a escola para ensinar as técnicas de produção de velas e sabonetes.

Por fim, todos os alunos do $1^{\circ}$ ao $5^{\circ}$ ano e as professoras reuniram-se no Salão Nobre da escola, com a intenção de socializar os conhecimentos que haviam sido adquiridos no decorrer desta pesquisa, em relação às plantas medicinais.

As observações das aulas evidenciaram uma pluralidade de metodologias utilizadas pelas professoras - especialmente pela professora em observação - para o desenvolvimento das atividades propostas no planejamento inicial.

$\mathrm{Na}$ presente pesquisa, todas as professoras disponibilizaram parte do seu tempo a elaborar e desenvolver estratégias e metodologias diferenciadas daquelas que estavam acostumadas a aplicar, confirmando o que escrevem Laburú e Carvalho (2001, p. 8) sobre o fato de que "um mestre pluralista não se recusa a experimentar uma outra proposta, pois a sua meta e o seu compromisso é com a aprendizagem dos alunos e não com uma fidelidade pedagógica".

$\mathrm{Na}$ Figura 1 são apresentadas as atividades planejadas pelas professoras participantes deste estudo, assim como as estratégias didáticas desenvolvidas pelas professoras em sala de aula, de acordo com a metodologia dos momentos pedagógicos.

Figura 1. Estratégias didáticas utilizadas pelas professoras.

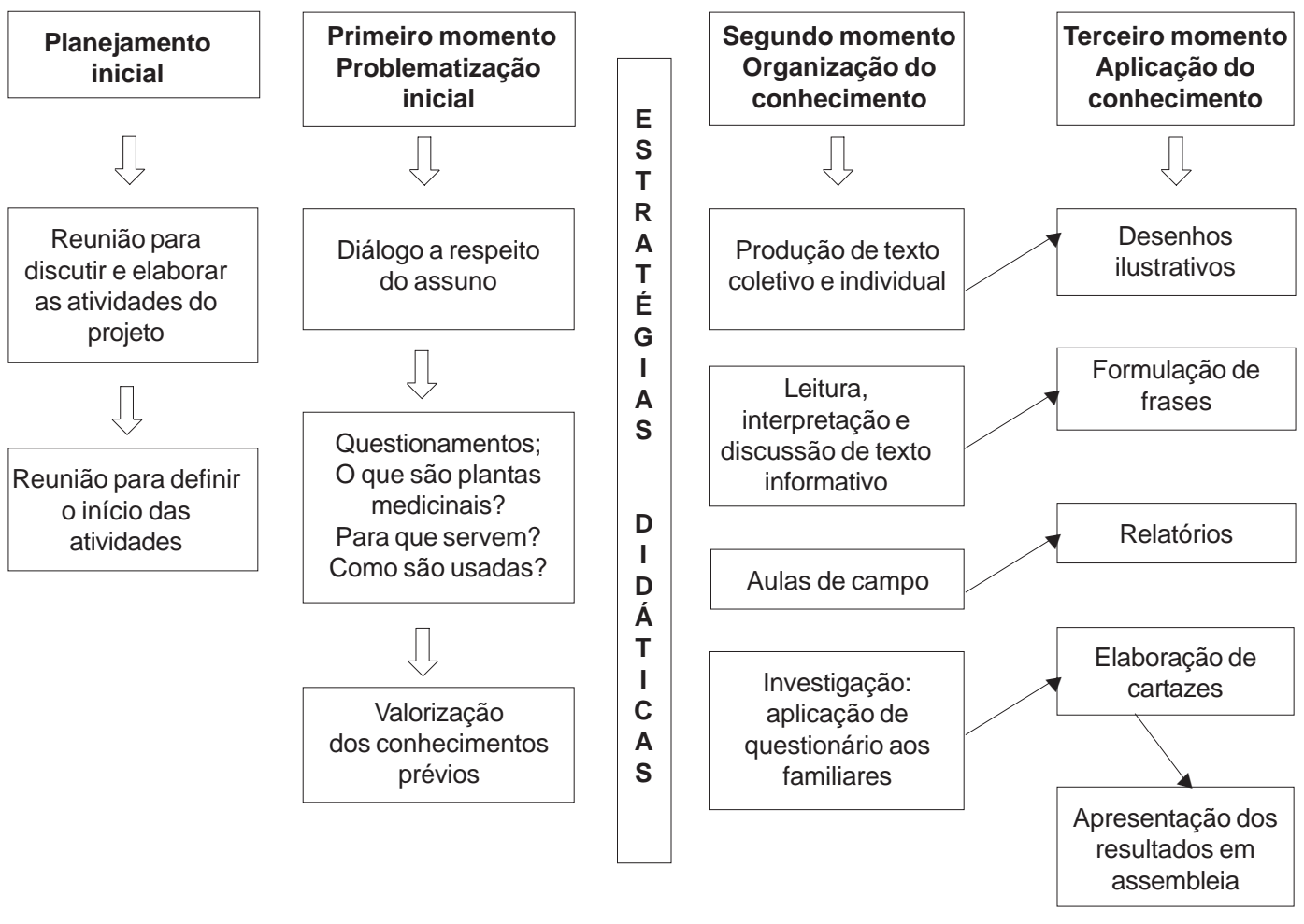

Fonte: Adaptado de Cachapuz, Praia e Jorge (2002). 
Kovalski, M. L.; Obara, A. T.

A metodologia utilizada pelas professoras está de acordo com os momentos pedagógicos propostos por Delizoicov e Angotti (2000). Esta metodologia se constitui de três momentos pedagógicos bem visíveis nas aulas, são eles:

- Primeiro momento: problematização inicial - quando são colocadas, aos alunos, questões e situações- problema a serem discutidas com os mesmos. Têm a função de motivar os alunos para a apresentação do conteúdo específico;

- Segundo momento: organização do conhecimento - neste momento, o conhecimento em Ciências Naturais, necessário à compreensão do tema e da problematização inicial, será sistematicamente estudado, sob orientação do professor. Serão apresentadas definições, conceitos e relações aos alunos;

- Terceiro momento: aplicação do conhecimento - destina-se, sobretudo, a criar estratégias para que os alunos consigam sistematizar o conhecimento trabalhado. Nesta etapa, o aluno tem a possibilidade de retomar as questões- problema iniciais ou voltar-se para outras situações, que podem ser explicadas pelo mesmo conhecimento.

\section{Considerações finais}

A pesquisa participante colocou a pesquisadora e as professoras como sujeitos ativos no trabalho coletivo, cada qual desempenhando seu papel, a fim de compreender a melhor forma de se trabalhar, com os alunos, a importância das plantas medicinais para a sociedade. Neste tipo de pesquisa ocorre um envolvimento mais próximo do pesquisador com a comunidade em estudo, pois ambos assumem uma postura investigativa, no sentido de desvelar problemas de sua própria realidade.

Todas as etapas preestabelecidas no planejamento inicial foram desenvolvidas pelas professoras, tendo, ainda, a inclusão de outras atividades no decorrer do projeto, como a realização de uma oficina para a produção de velas e sabonetes, utilizando a tintura da citronela.

O planejamento possibilitou que as professoras discutissem, de forma coletiva, a respeito de diversas atividades e estratégias didáticas que seriam desenvolvidas durante todo o ano, voltadas ao estudo das plantas medicinais. O planejamento foi seguido sistematicamente e, com isso, as professoras vivenciaram e comprovaram que é possível trabalhar coletivamente um tema em comum - no caso, "plantas medicinais" _ de maneira transversal, envolvendo diferentes disciplinas e turmas de alunos, com resultados positivos e benéficos a todos os participantes.

As professoras não se restringiram às aulas expositivas tradicionais, mas utilizaram uma pluralidade de metodologias e modalidades didáticas no desenvolvimento das várias etapas do projeto: valorização dos conhecimentos prévios dos alunos, diálogo e problematização dos vários conceitos e temas, elaboração de texto coletivo, visitas ao horto medicinal, leitura e interpretação de texto informativo, produção de texto, aulas de campo, práticas investigativas, elaboração de cartazes, desenhos ilustrativos, socialização dos conhecimentos e realização de oficina temática. Diferentes estratégias didáticas possibilitaram um maior envolvimento dos alunos nas atividades previstas desde o inicio do projeto.

A implantação do horto medicinal na escola proporcionou, aos alunos, um maior contato com as plantas e com a terra, na medida em que construíam e plantavam as espécies medici- 
O estudo da etnobotânico das plantas medicinais ...

nais, além de servir de instrumento didático na exploração de várias temáticas, entre elas: compostagem, adubação orgânica, preservação da biodiversidade, importância das plantas medicinais etc.

Vale destacar, ainda, que os alunos puderam aprimorar e desenvolver suas habilidades em Língua Portuguesa, na medida em que tiveram que produzir os inúmeros registros escritos (textos coletivos, textos individuais, frases, relatórios, cartazes, entre outros) durante as aulas. As professoras exploraram, também, a oralidade dos alunos, por meio: de diálogos e conversas durante as aulas, da apresentação dos resultados em assembleia, da entrevista com os familiares etc. Toda a trajetória de estudos e práticas vivenciadas pelas professoras e alunos, ao longo deste estudo, propiciou uma aprendizagem em relação às plantas medicinais, assim como os cuidados e orientações que devem ser tomadas ao utilizá-las.

O trabalho colocou em evidência que as escolas, inclusive, as escolas rurais, necessitam se voltar mais aos saberes do cotidiano, problematizar os conhecimentos tradicionais e populares que fazem parte da vida e da cultura dos seus alunos, para que estes possam construir uma leitura mais crítica sobre a realidade em que vivem.

\section{Referências}

ALBUQUERQUE, U. P. Introdução a etnobotânica. 2. ed. Rio de Janeiro: Interciência, 2005.

AMOROZO, M. C. M. A abordagem etnobotânica na pesquisa de plantas medicinais. In: DI STASI, L. D. (Org.). Plantas medicinais: arte e ciência - um guia de estudo interdisciplinar. São Paulo: Editora da Unesp, 1996. p. 47-68.

ARENAS, A.; CAIRO, C. Etnobotánica, modernidad y pedagogía crítica del lugar. Utopía y Praxis Latinoamericana, Punto Fijo, v. 14, n. 44, p. 69-83, 2009.

BARBOSA, M. C. S. Trabalhando com projetos na educação infantil. In: XAVIER, M. L.; DALLA ZEN, M. I. (Org.). Planejamento em destaque: análises menos convencionais. Porto Alegre: Mediação, 2000.

BRANDÃO, C. R. A pergunta a várias mãos: a experiência da pesquisa no trabalho do educador. São Paulo: Cortez, 2003.

Repensando a pesquisa participante. São Paulo: Brasiliense, 1984.

BRASIL. Ministério da Educação. Secretaria de Educação Básica. Indagações sobre currículo: currículo, conhecimento e cultura. Brasília, 2007. Disponível em: <http:// portal.mec.gov.br/seb/arquivos/pdf/Ensfund/indag3.pdf>. Acesso em: 23 set. 2013.

Ministério da Educação e do Desporto. Parâmetros curriculares nacionais: introdução aos parâmetros curriculares nacionais. Brasília, 1997. v. 1.

. Ministério da Saúde. Política nacional de plantas medicinais e fitoterápicos. Brasília, 2006. 
Kovalski, M. L.; Obara, A. T.

CACHAPUZ, A.; PRAIA, J.; JORGE, M. Ciência, educação em ciência e ensino das ciências. Lisboa: Ministério da Educação, 2002.

CHASSOT, A. Alfabetização científica: questões e desafios para a educação. 4. ed. Ijuí: Ed. Unijuí, 2006.

COBERN, W. W.; LOVING, C. C. Defining science in a multicultural world: implications for science education. Science Education, Hoboken, v. 85, n. 1, p. 50-67, 2001.

COSTA, R. G. A. Os saberes populares da etnociência no ensino das ciências naturais: uma proposta didática para aprendizagem significativa. Didática Sistêmica, Rio Grande, v. 8, p. 162-172, 2008.

CUNHA, A. P. Aspectos históricos sobre plantas medicinais, seus constituintes activos e fitoterapia. In: CUNHA, A. P.; ROQUE, O. R.; SILVA, A. P. Plantas e produtos vegetais em fitoterapia. Lisboa: Fundação Calouste Gulbenkian, 2003. Disponível em: < http:// antoniopcunha.com.sapo.pt/ahspmscaf.htm>. Acesso em: 20 fev. 2010.

DELIZOCOV, D.; ANGOTTI, J. A. Metodologia do ensino de ciências. 2. ed. São Paulo: Cortez, 2000.

DIAS, A. S.; JANEIRA, A. L. Entre ciências e etnociências. Episteme, Porto Alegre, n. 20, p. 107-127, 2005. (Suplemento especial).

FREIRE, P. Pedagogia do oprimido. 17. ed. Rio de Janeiro: Paz e Terra, 1987.

GIANOTTEN, V.; WIT, T. Pesquisa participante em um contexto de economia camponesa. In: BRANDÃO, C. R. (Org). Repensando a pesquisa participante. São Paulo: Brasiliense, 1984. p. 158-188.

HAMILTON, A. C. et al. The purposes and teaching of applied ethnobotany. Godalming: WWF, 2003. (People and plants working paper, 11). Disponível em: <http:// unesdoc.unesco.org/images/0014/001458/145847e.pdf>. Acesso em: 23 set. 2013.

KRASILCHIK, M. Prática de ensino de biologia. 4. ed. São Paulo: Edusp, 2004.

LABURÚ, C. E.; CARVALHO, M. Controvérsias construtivistas e pluralismo metodológico no ensino de ciências naturais. Revista Brasileira de Pesquisa em Educação em Ciências, São Paulo, v. 1, n. 1, p. 1-11, 2001. Disponível em: <http://revistas.if.usp.br/ rbpec/article/viewArticle/216>. Acesso em: 23 set. 2013.

LOPES, A. R. C. Conhecimento escolar: ciência e cotidiano. Rio de Janeiro: Ed. UERJ, 1999.

Reflexões sobre currículo: as relações entre senso comum, saber popular e saber escolar. Em Aberto, Brasília, v. 12, n. 58, p. 15-22, 1993. Disponível em: <http:// emaberto.inep.gov.br/index.php/emaberto/article/viewFile/852/764>. Acesso em: 23 set. 2013. 
O estudo da etnobotânico das plantas medicinais ...

LOPES, F.; BETTENCOURT, T. O ensino da biologia numa perspectiva por pesquisa: contributos de uma investigação preliminar no ensino secundário. Enseñanza de las Ciencias, Barcelona, p. 508-511, 2009. (Número extra: VIII Congreso Internacional sobre Investigación en Didáctica de las Ciencias, 8, 2009, Barcelona).

LUCAS, S.; VASCONCELOS, C. Perspectivas de ensino no âmbito das práticas lectivas: um estudo com professores do $7^{\circ}$ ano de escolaridade. Revista Electrónica de Enseñanza de las Ciências, Vigo, v. 4, n. 3, 2005. Disponível em: <http://reec.uvigo.es/volumenes/ volumen4/ART4_Vol4_N3.pdf >. Acesso em: 23 set. 2013.

MOREIRA, A. F. B.; CANDAU, V. M. Educação escolar e cultura (s): construindo caminhos. Revista Brasileira de Educação, Rio de Janeiro, n. 23, p. 156-168, maio/ago. 2003.

MORTIMER, E. F. Sobre chamas e cristais: a linguagem cotidiana, a linguagem científica e o ensino de ciências. In: CHASSOT, A.; OLIVEIRA, R. J. (Org.). Ciência, ética e cultura na educação. São Leopoldo: Ed. Unisinos, 1998. p. 99-118.

PEIXOTO NETO, P. A. S.; CAETANO, L. C. Plantas medicinais: do popular ao científico. Maceió: Edufal, 2005.

PERRELLI, M. A. S. "Conhecimento tradicional” e currículo multicultural: notas com base em uma experiência com estudantes indígenas Kaiowá/Guarani. Ciência \& Educação, Bauru, v. 14, n. 3, p. 381-396, 2008.

SANTOMÉ, J. T. As culturas negadas e silenciadas no currículo. In: SILVA, T. T. (Org.). Alienígenas na sala de aula: uma introdução aos estudos culturais em educação. 6. ed. Petrópolis: Vozes, 1995. p. 159-177.

SILVA, M. C. Conhecimento científico e o saber popular sobre os moluscos nos terreiros de candomblé de Recife e Olinda, estado de Pernambuco. 2006. $111 \mathrm{f}$. Dissertação (Mestrado em Educação) - Universidade Federal da Paraíba, João Pessoa, 2006.

THIOLLENT, M. Metodologia da pesquisa-ação. São Paulo: Cortez, 1986.

WERMANN, A. M.; VELLOSO, C. C.; FUSIGER, T. B. Horto medicinal comunitário: relógio do corpo humano. Revista Brasileira de Agroecologia, Cruz Alta, v. 2, n. 1, p. 670-673, 2007. 